\title{
Introduction of the Neuropsychology Review Board of Editors: 2011-2013
}

\author{
Edith V. Sullivan
}

Received: 30 October 2011 / Accepted: 7 November 2011 /Published online: 17 November 2011

(C) Springer Science+Business Media, LLC 2011

In assuming the role of editor-in-chief of Neuropsychology Review and introducing the theme of putting the "neuro" back into neuropsychology, I had the privilege of appointing a new slate of Associate Editors. These four editorsIda Sue Baron, William Barr, Rosemary Fama, Susan Tapert-represent diverse areas of our discipline and thus contribute invaluably to editorial decisions, including choice of reviewers. Each serves as an essential "extender" of and consultant to me.

Also in keeping with the new theme comes a change in the membership of the Editorial Board, which I am now announcing with this issue of the journal. It took three full years to consider the new complexion of the board, with intensive input from my four Associate Editors. After achieving concurrence amongst the five of us on the list of scientists to retire $(n=31)$, retain $(N=16)$, and newly invite $(N=20)$, I wrote letters to each person. Now, I present to the Neuropsychology Review readership the editorial board members for December 2011 to December 2013, the remaining years of my tour of duty. The list includes only invitees who responded affirmatively to my invitation.

As I expressed in my letters to the prior and new editorial board members, the goal in changing the board was to keep within the current scope and aims of the journal and to open editorial opportunities to the new generation of neuropsychologists and neuroscientists. Supplanting the old with the new is difficult, hurtful to some, and potentially "politically incorrect." Herein I apologize to those who feel slighted by the change. Equally, I extend my thanks to those retirees who responded positively to this chance for change. Indeed, I thank all of the retiring editorial board members for their years of service under my direction and for the many more years of review and consultation under the editorships of my predecessors, Gerald Goldstein, Anthony Puente, and Ronald Lazar.
E. V. Sullivan $(\bowtie)$

Department of Psychiatry \& Behavioral Sciences,

Stanford University School of Medicine,

Stanford, CA 94305, USA

e-mail: edie@stanford.edu 